\title{
Biometria da cabeça e da cavidade craniana de ovinos deslanados sem raça definida (Ovis aries LINNAEUS, 1758) em Petrolina/Pernambuco, Brasil
}

\author{
Biometry of head and cranial cavity of wooless mongrel sheep (Ovis aries LINNAEUS, 1758) \\ in Petrolina/Pernambuco, Brazil
}

\author{
Fernando Santos COSTA ${ }^{1}$; Rafael Torres de Souza RODRIGUES ${ }^{2}$; Carlos Wagner de Souza \\ WANDERLEY ${ }^{1}$; Joaquim PEREIRA NETO ${ }^{3}$; Marcelo Domingues de FARIA ${ }^{1}$ \\ ${ }^{1}$ Curso de Medicina Veterinária da Universidade Federal do Vale do São Francisco, Petrolina - PE, Brasil \\ ${ }^{2}$ Curso de Pós-graduação em Ciência Animal na Universidade Federal do Vale do São Francisco, Petrolina - PE, Brasil \\ ${ }^{3}$ Professor Assistente da Área de Estatística da Universidade do Estado da Bahia, Juazeiro - BA, Brasil
}

\begin{abstract}
Resumo
A espécie ovina é largamente utilizada na região Nordeste do Brasil por apresentar alta rusticidade. No entanto, sua anatomia ainda é pouco estudada. Assim, crescem os estudos para gerar subsídios técnico-científicos àqueles profissionais que trabalham com as áreas aplicadas da Medicina Veterinária e afins. O objetivo do presente estudo foi estabelecer correlações entre as dimensões da cabeça e da cavidade craniana, utilizando 80 ovinos, 40 machos e 40 fêmeas, com média de peso entre 27,0 e 33,0 kg. Em fêmeas, foi observada correlação entre a massa corpórea e o comprimento da cabeça; entre a massa corpórea e largura da cabeça; entre o comprimento da cabeça e sua respectiva largura; entre comprimento da cabeça e o comprimento da cavidade craniana e entre a altura da cabeça e o comprimento da cavidade craniana. As demais dimensões, nas fêmeas, não tiveram correlação estatisticamente significativa. Já em animais do sexo masculino, foi possível evidenciar correlação apenas entre a altura da cabeça e altura da cavidade craniana. Desta forma, é possível concluir que, quanto maiores forem as proporções da cabeça, maiores serão as dimensões e volume intracranianos.
\end{abstract}

Palavras-chave: Biometria. Cabeça. Cavidade craniana. Ovinos.

\begin{abstract}
The sheep is a commonly used species in Northeast region of Brazil because of its high rusticity. Yet, very little is known about the anatomy of these species. Therefore, the number of studies in this field is increasing to stimulate technical and scientific subsidies to professionals in Veterinary Medicine. The aim of this study was to establish correlations between the head and cranial cavity dimensions, using 80 sheep, 40 males and 40 females, with a medium weight of 27,0 to 33,0 $\mathrm{kg}$. In females, it was observed correlation between corporal weight and length of the head; corporal weight and width of the head; length of the head and its respective width; length of the head and length of the cranial cavity; height of the head and length of the cranial cavity. The other dimensions, in females, had non-significant correlation. In males, the only correlation established was between height of the head and height of the cranial cavity. Thus, it was possible to conclude that the larger the proportions of the cranium are, the larger will be the dimensions and the intracranial volume.
\end{abstract}

Keywords: Biometry. Head. Cranial cavity. Sheep.

\section{Introdução}

Os ovinos constituem uma subfamília de mamíferos da Ordem Artiodactyla, Família Bovidae, com único gênero Ovis, representado por grande número de espécies selvagens e por uma domesticada, Ovis Áries, as quais pertencem numerosas raças disseminadas por todo o mundo, originárias nas zonas mais elevadas do centro da Ásia, irradiando-se posteriormente à Europa.
Muitas das raças ovinas foram, por séculos, melhoradas para a produção de lã fina, processo que resultou em mais de 200 raças diferentes. No Brasil, o

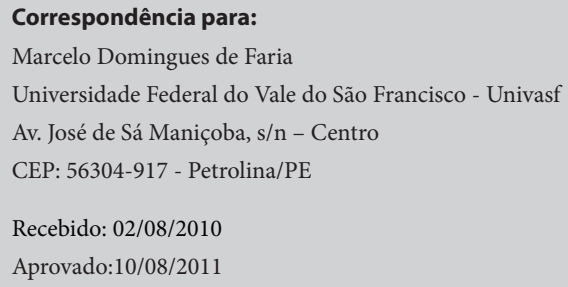


rebanho ovino teve início com a colonização portuguesa, em praticamente toda a faixa litorânea, tendo melhor se adaptado, e expandido intensamente, na região Nordeste, com destaque para as raças típicas da península ibérica e da África. Esses animais mostram características típicas de clima tropical, caracterizando-se pela ausência de lã, porte pequeno a médio e maior rusticidade.

O último censo agropecuário, realizado entre os anos de 1995 e 1996, registrava um rebanho ovino nordestino da ordem de 6,2 milhões de cabeças, perfazendo $48 \%$ do rebanho nacional. Esses números demonstraram que o rebanho de ovinos, no Nordeste, ultrapassara o de caprinos, sendo a Bahia, o Estado com maior rebanho nacional de ovinos, com dois milhões de cabeças, correspondendo a $14,4 \%$ deste rebanho ${ }^{1}$.

De acordo com dados estatísticos ${ }^{1}$, de 1996 a 2004, o rebanho nacional de ovinos teve um incremento de 7,91\%, atingindo 15,06 milhões de cabeças, enquanto no Nordeste, durante o mesmo período, o incremento foi de $29,69 \%$. Todavia a densidade populacional de ovinos na região Nordeste é de 5,24 cabeças $/ \mathrm{km}^{2}$, onde as maiores concentrações estão nas microrregiões do Médio Jaguaribe, no Ceará, e Serrinha na Bahia. Em 2005, o rebanho de ovinos atingiu 16,05 milhões de cabeças, e a região Nordeste detém, atualmente, $56,3 \%$ desse rebanho ${ }^{1}$.

$\mathrm{O}$ esqueleto completo da cabeça compreende o crânio, a maxila, a mandíbula, o aparelho hioide, os ossículos da orelha média e as cartilagens da orelha externa, do nariz e da laringe ${ }^{2}$. Já, o crânio é um complexo de ossos moldados em cartilagem, na maioria pares, mas alguns medianos e ímpares, que se encaixam perfeitamente para formar uma única estrutura rígida ao redor do encéfalo, os órgãos dos sentidos especiais (visão, olfato, audição, equilíbrio e gustação), as aberturas para as passagens de ar e alimento e a maxila e mandíbula, incluindo os dentes para a mastigação ${ }^{3,4}$. A cavidade craniana contém o encéfalo com seus revestimentos e vasos. O teto da caixa encefálica é formado pelos ossos parietais e frontais; os dois terços rostrais da base do crânio são formados pelos ossos esfenoides; o terço caudal é formado pelos ossos occipital e temporais; a parede caudal é composta pelo osso occipital; a parede rostral é a lâmina crivosa do osso etmoide. As paredes laterais são formadas pelos ossos temporais, parietais, frontais e esfenoides ${ }^{3}$.

A cavidade craniana situa-se logo caudal às cavidades nasais, estendendo-se até a parede caudal do crânio. $\mathrm{O}$ interior da cavidade craniana apresenta uma correspondência razoavelmente maior que os contornos do encéfalo, apesar de ser necessário um significativo espaço intracraniano para as meninges e os espaços intermeníngeos que circundam o encéfalo ${ }^{2}$.

No que se refere à biometria da cabeça e da cavidade craniana, Kalita et al. ${ }^{5}$, em estudo para determinar as dimensões destas em caprinos, encontraram os seguintes resultados: $24,74 \pm 0,21 \mathrm{~cm}$ de comprimento e 17,35 $\pm 0,24 \mathrm{~cm}$ de largura, sendo que os mesmo não apresentaram correlação com o comprimento da cavidade craniana nem com seu volume, que apresentaram, respectivamente, $11,71 \pm 0,08 \mathrm{~cm}$ e $135,38 \pm 0,33 \mathrm{~cm}^{3}$.

Já Sarma $^{6}$, visando determinar as características morfológicas da cabeça de 46 (quarenta e seis) caprinos da raça Kagani, obteve diferentes parâmetros cranianos, onde, para obtenção da biometria da cabeça foi utilizado escala e paquímetro, encontrando, para comprimento e largura da cabeça, $24,72 \pm 0,93 \mathrm{~cm}$ e $10.40 \pm$ $0,61 \mathrm{~cm}$, respectivamente, e para a realização da biometria da cavidade craniana, preencheu-se os forames da cavidade craniana que possuem conexão com a cabeça, sendo este espaço posteriormente preenchido com grãos de mostarda através do forame magno e, em seguida, colocados em proveta graduada para obtenção do volume da cavidade intracraniana, obtendo para esta 113,0 $\pm 0,84^{3}$, mostrando uma correlação linear da cavidade craniana com a largura da cabeça.

Rodrigues et al. ${ }^{7}$, em pesquisa utilizando 64 caprinos sem raça definida, adultos, de diferentes idades, 
sendo 32 machos e 32 fêmeas, obtiveram as dimensões do crânio e da cavidade craniana com auxílio de fita métrica e paquímetro e, para o volume intracraniano, foram introduzidos balão de látex na cavidade craniana, através do forame magno, o qual posteriormente era preenchido com água e transferida para proveta graduada. Os resultados foram expressos em milímetros, para comprimento, largura e altura do crânio, os quais foram respectivamente: $218,01 \pm 6,96,120,17 \pm$ 10,01 e $108,14 \pm 4,46$. Já o comprimento, a largura e a altura da cavidade craniana foram, respectivamente: $109,31 \pm 7,25,61,36 \pm 4,51$ e $63,85 \pm 2,88$; enquanto seu volume foi de $119,31 \mathrm{~cm}^{3} \pm 12,21$. Constatando que a largura do crânio possui correlações significativas positivas com o comprimento, a altura e volume da cavidade craniana. Ainda, evidenciaram-se diferenças significativas entre machos e fêmeas, em relação às dimensões da cabeça e da cavidade craniana, porém, não houve diferença do volume intracraniano em função do sexo dos caprinos.

Golalipour, Jahanshaei e Haidari ${ }^{8}$, avaliram a capacidade craniana em 808 pessoas normais, das quais 401 pertenciam ao grupo Turkman (198 homens e 203 mulheres) e 407 nativos Fars (200 homens e 207 mulheres), com idade entre 17-20 anos, em Gorgan Sudeste do Mar Cáspio fronteira com o Norte do Irã. A média e o desvio padrão da capacidade craniana dos Turkmans, para homens e mulheres, foram 1420,6 $\pm 85 \mathrm{ml}$ e 1227,2 $\pm 120 \mathrm{ml}$, respectivamente; e para os nativos do grupo Fars $1369 \pm 142 \mathrm{ml}$ e $1215,8 \pm 125 \mathrm{ml}$, para homens e mulheres, simultaneamente - mostrando diferença estatisticamente significativa $(\mathrm{P}<0,05)$, constatando que a capacidade craniana é mais elevada em homens do que em mulheres.

No entanto, Acer et al. ${ }^{9}$, avaliaram de 28 (vinte e oito) crânios humanos, onde no interior da cavidade craniana foi colocado um balão de borracha, o qual posteriormente era preenchido com água, sendo o líquido presente no interior do balão transferido para um recipiente de vidro graduado, obtendo média de $1311 \pm 133 \mathrm{~cm}^{3}$ para o volume da cavidade craniana.

Para determinar a biometria da cavidade craniana e seu respectivo volume, Sahin et al. ${ }^{10}$, em 20 crânios humanos (dez homens e dez mulheres), utilizaram um método no qual era introduzido, através do forame magno, um balão na cavidade craniana, sendo este espaço preenchido com água e, em seguida, o líquido vertido em proveta graduada, obtendo assim o seu volume. A média e o desvio padrão do volume intracraniano obtidos pelo método de preenchimento da cavidade craniana por água foram de 1,262.0 \pm $160.4 \mathrm{~cm}^{3}\left(1,389.5 \pm 96.5 \mathrm{~cm}^{3}\right.$ para o sexo masculino e $1,134.5 \pm 94.3 \mathrm{~cm}^{3}$ para o sexo feminino, respectivamente).

Já Robina et al. ${ }^{11}$, em análise para determinar o volume da cavidade craniana em cães galgos da raça Greyhound, e utilizando tomografia computadorizada axial de varredura, constataram que o volume variou de $113,7 \mathrm{~cm}^{3}$ a $116,5 \mathrm{~cm}^{3}$, nos machos, e 106 $\mathrm{cm}^{3}$ e $109,4 \mathrm{~cm}^{3}$, nas fêmeas, havendo, estatisticamente, variação significativa no volume intracraniano de ambos os sexos. Resultados semelhantes foram encontrados por Hwang et al. ${ }^{12}$, que determinaram a capacidade craniana em humanos coreanos adultos, utilizando o método do preenchimento da cavidade craniana com sementes de arroz, sendo as sementes posteriormente colocadas em um cilindro graduado para determinação da capacidade craniana, obtendo média de $1470 \mathrm{~cm}^{3} \pm 107$ para os homens e $1317 \mathrm{~cm}^{3} \pm$ 117 para mulheres, constatando que os grupos (masculino e feminino) diferiram estatisticamente entre si.

Acer et al. ${ }^{13}$, em avaliação da capacidade craniana em 366 estudantes universitários saudáveis (226 homens e 140 mulheres), com idade entre 17 e 26 anos, utilizando as dimensões da cabeça (comprimento, largura e altura), verificaram como resultado uma média e desvio padrão para homens e mulheres de $1411,64 \mathrm{~cm}^{3} \pm 118,9$ e $1306,95 \mathrm{~cm}^{3} \pm 162,9$, respectivamente. Isso demonstra significativa diferença entre os 
sexos, o que permitiu aos pesquisadores constatar que a capacidade craniana é maior nos indivíduos do sexo masculino do que feminino.

O objetivo do presente trabalho foi determinar a biometria do crânio e da cavidade craniana de animais da espécie ovina (Ovis aries LINNAEUS, 1758).

\section{Material e Método}

Foram utilizados 80 ovinos (Ovis aries LINNAEUS, 1758), sem padrão racial definido (SRD), sendo 40 machos e 40 fêmeas, com massa corpórea entre 27,0 e $33,0 \mathrm{~kg}$, oriundos do Abatedouro Municipal de Petrolina, Estado de Pernambuco.

Previamente ao abate, os animais tinham a massa corporal aferida, utilizando, para tanto, balança digital analítica (Filizola Personal III ${ }^{\circledast}$, Indústrias Filizola S.A., São Paulo - SP, Brasil), sendo identificados adequadamente.

A forma de abate adotada, para evitar danificação de estruturas cranianas, foi a secção da medula espinhal, na altura da articulação atlanto-occipital. Após a decapitação, o material era, então, transportado ao Laboratório de Anatomia dos Animais Domésticos e Silvestres do Campus Ciências Agrárias da Universidade Federal do Vale do São Francisco (UNIVASF), no qual se promoveu o rebatimento da cútis, da musculatura e demais tecidos adjacentes, com auxílio de material de dissecação, sendo, em seguida, imersos em água para macerar, por tempo não superior a três dias, quando removeram-se resíduos ainda encontrados, deixando a cabeça limpa, de modo a permitir a determinação da biometria.

As mensurações externas da cabeça (comprimento, largura e altura) foram realizadas por meio de fita métrica milimetrada (Coats Corrente, São Paulo - SP, Brasil). Com auxílio de paquímetro de aproximação milimetral (Vonder, Curitiba - PR, Brasil) aferiu-se altura, largura e comprimento da cavidade craniana.
O volume da cavidade craniana foi aferido por meio de balão volumétrico à base de látex (Fábrica de Artefatos São Roque S. A., São Roque - SP, Brasil), introduzido através do forame magno e, posteriormente, preenchido com água, de modo a ocupar todos os espaços. Em seguida, o conteúdo do balão era liberado em proveta graduada, obtendo, desta forma, seu volume intracraniano, representado em centímetros cúbicos $\left(\mathrm{cm}^{3}\right)$.

A análise estatística foi realizada através do programa Statistic Analysis System - SAS (2006), sendo, utilizado o teste de correlação de Pearson para encontrar a matriz de correlação entre as variáveis. Foram consideradas apenas as correlações maiores que 0,5. Para promover a análise de variância e verificar as diferenças de correlação entre os sexos em relação às variáveis estudadas, foram utilizados o Procedure CORR e o Procedure GLM, respectivamente. Os animais foram distribuídos conforme as correlações estabelecidas.

\section{Resultados}

Os dados relativos à massa corporal, comprimento, altura e largura da cabeça, bem como comprimento, largura, altura e volume da cavidade craniana, com média e desvio padrão, estão elucidados na tabela 1 , a qual permite verificar que os parâmetros biométricos da cabeça dos machos são maiores que em fêmeas, excetuando-se apenas o comprimento da cabeça. Vale salientar que, a média da massa corporal das fêmeas foi maior que dos machos.

Os resultados obtidos na biometria da cabeça e da cavidade craniana de ovinos, levando em consideração apenas os animais do sexo feminino, estabeleceu como padrão, uma variável $(r)$ maior que 0,5 . Por meio da análise estatística, foi observada correlação estatística significativa entre a massa corpórea e o comprimento da cabeça; entre a massa corpórea e largura da cabeça; entre o comprimento da cabeça e sua respectiva largura; entre comprimento da cabeça e o comprimento da cavidade craniana; entre a altura da 
Tabela 1 - Determinação da média e desvio padrão das dimensões da cabeça e da cavidade craniana de ovinos deslanados sem raça definida (Ovis aries LINNAEUS, 1758) - Petrolina - 2010

\begin{tabular}{|l|c|c|}
\hline \multirow{2}{*}{ Variável } & \multicolumn{2}{c}{ Média e Desvio Padrão } \\
\cline { 2 - 3 } & Machos & Fêmeas \\
\hline Massa Corporal $(\mathrm{Kg})$ & $29,92 \pm 1,492$ & $30,00 \pm 1,267$ \\
Comprimento da Cabeça $(\mathrm{mm})$ & $219,2 \pm 5,793$ & $220,9 \pm 7,111$ \\
\hline Altura da Cabeça $(\mathrm{mm})$ & $74,72 \pm 4,907$ & $71,27 \pm 4,197$ \\
Largura da Cabeça $(\mathrm{mm})$ & $111,5 \pm 4,486$ & $108,5 \pm 3,796$ \\
\hline Comprimento da Cavidade Craniana $(\mathrm{mm})$ & $105,0 \pm 4,830$ & $99,42 \pm 3,207$ \\
Altura da Cavidade Craniana $(\mathrm{mm})$ & $66,65 \pm 2,587$ & $63,42 \pm 1,935$ \\
\hline Largura da Cavidade Craniana $(\mathrm{mm})$ & $66,77 \pm 2,422$ & $64,12 \pm 2,172$ \\
Volume da Cavidade Craniana $\left(\mathrm{cm}^{3}\right)$ & $114,5 \pm 7,500$ & $110,7 \pm 8,621$ \\
\hline
\end{tabular}

Legenda: $\mathrm{mm}$ - milímetros $/ \mathrm{cm}^{3}$ - centímetros cúbicos / kg - quilograma

cabeça e comprimento da cavidade craniana. As demais dimensões não apresentaram correlação, como pode ser observado na figura 1 .

Já considerando os animais do sexo masculino, estabelecendo a variável padrão ( $\mathrm{r}$ ) maior que 0,5 , foi possível evidenciar correlação apenas entre a altura da cabeça e a altura da cavidade craniana, enquanto as demais dimensões não apresentaram correlação estatística significativa, como pode ser observado na figura 2.

\section{Discussão}

O método utilizado para aferir o volume intracraniano de ovinos foi o mesmo utilizado por Sahin et al. ${ }^{10}$, para obter o volume intracraniano de 20 crânios humanos (dez homens e dez mulheres), que utilizaram método no qual era introduzido, através do forame magno, um balão na cavidade craniana, sendo este espaço preenchido com água e, em segui$\mathrm{da}$, o líquido vertido em proveta graduada, obtendo assim o seu volume. A média e o desvio padrão do volume intracraniano obtidos pelo método de preenchimento da cavidade craniana por água foram de $1,262.0 \pm 160.4 \mathrm{~cm}^{3}\left(1,389.5 \pm 96.5 \mathrm{~cm}^{3}\right.$ para o sexo masculino e $1,134.5 \pm 94.3 \mathrm{~cm}^{3}$ para o sexo feminino, respectivamente).
A biometria da cabeça e da cavidade craniana da espécie ovina mostrou que os machos possuem o volume da cavidade craniana maior que as fêmeas, o que também foi observado por Robina et al. ${ }^{11}$, em estudo para determinar o volume da cavidade craniana em cães galgos da raça Greyhound, utilizando tomografia computadorizada axial de varredura, no qual constataram que o volume variou de $113,7 \mathrm{~cm}^{3}$ a 116,5 $\mathrm{cm}^{3}$, nos machos, e $106 \mathrm{~cm}^{3}$ e $109,4 \mathrm{~cm}^{3}$, nas fêmeas, havendo, estatisticamente, variação significativa no volume intracraniano de ambos os sexos. Em outro estudo, resultados semelhantes foram encontrados por Hwang et al. ${ }^{12}$, que determinaram a capacidade craniana em humanos coreanos adultos, utilizando o método do preenchimento da cavidade craniana com sementes de arroz, sendo as sementes posteriormente colocadas em um cilindro graduado para determinação da capacidade craniana, obtendo média de 1470 $\mathrm{cm}^{3} \pm 107$ para os homens e $1317 \mathrm{~cm}^{3} \pm 117$ para mulheres, constatando que os grupos (masculino e feminino) diferiram estatisticamente entre si.

Utilizando método idêntico ao empregado no presente trabalho, Rodrigues et al. ${ }^{7}$, em pesquisa para determinar as dimensões da cabeça e da cavidade craniana e o volume intracraniano em 64 caprinos adultos (32 machos e 32 fêmeas) sem raça definida e 


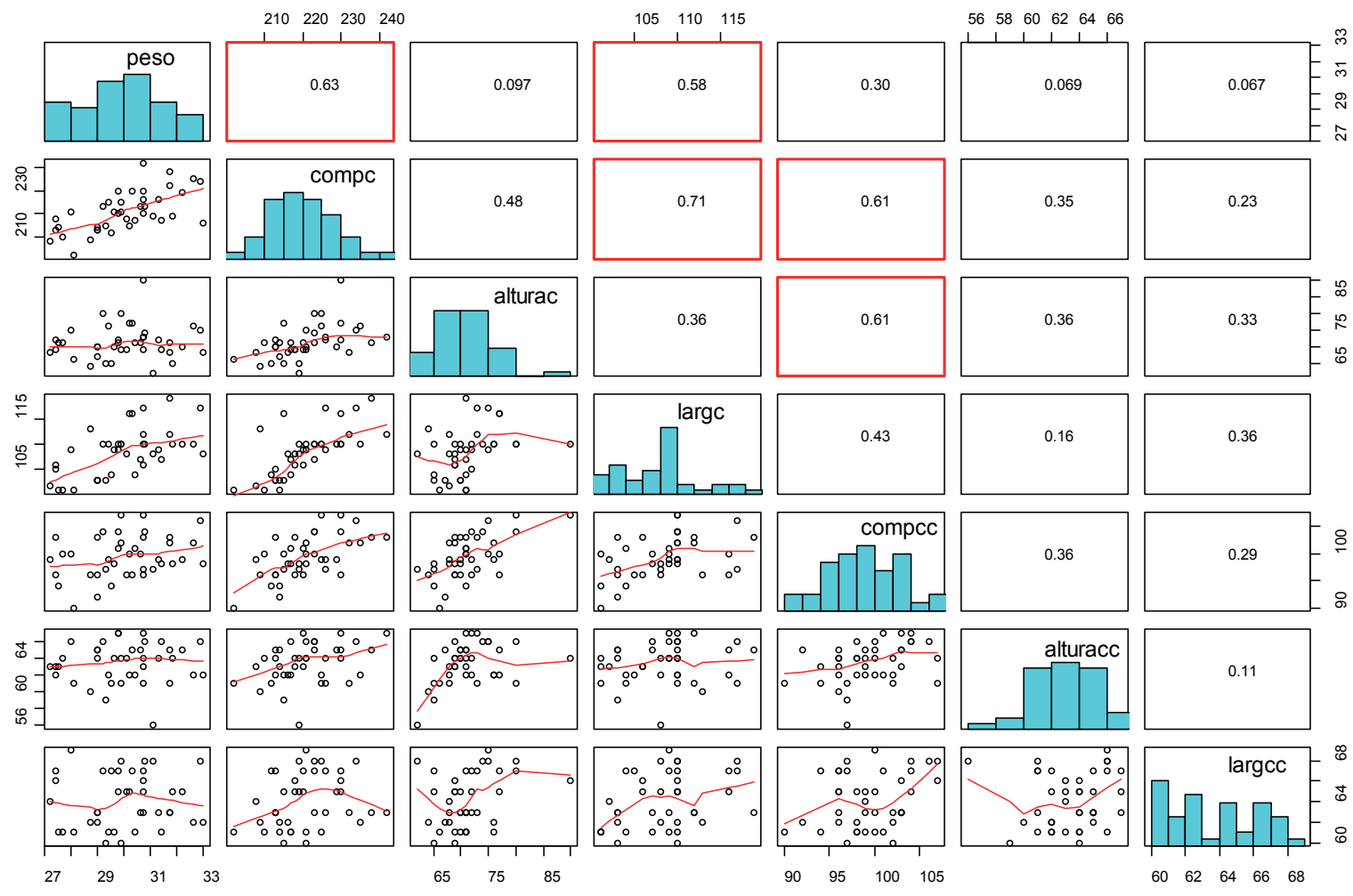

Legenda: peso - massa corporal / compc - comprimento da cabeça / alturac - altura da cabeça / largc - largura da cabeça / compcc comprimento da cavidade craniana / alturacc - altura da cavidade craniana / largcc - largura da cavidade craniana

Figura 1 - Gráfico evidenciando matriz de dispersão e coeficiente de correlação de Pearson entre massa corporal e dados da cabeça e cavidade craniana de ovinos deslanados sem raça definida do sexo feminino, considerando $(r>0,5)$ - Petrolina - 2010

de diferentes idades, obtiveram, com relação às medidas da cabeça, $218,01 \mathrm{~mm} \pm 6,96$ para comprimento; $120,17 \mathrm{~mm} \pm 10,01$ para largura; e $108,14 \mathrm{~mm} \pm 4,46$, para altura. Já, o comprimento, a largura, a altura e o volume da cavidade craniana, foram respectivamente: $109,31 \mathrm{~mm} \pm 7,25,61,36 \mathrm{~mm} \pm 4,51,63,85 \mathrm{~mm} \pm 2,88$ e $119,31 \mathrm{~cm}^{3} \pm 12,21$. Os autores constataram, ainda, que a largura da cabeça possui correlações significativas positivas com o comprimento, altura e volume da cavidade craniana. Evidenciaram, também, diferenças significativas entre machos e fêmeas, em relação às dimensões da cabeça e da cavidade craniana. No entanto, não houve diferença do volume intracraniano em função do sexo dos caprinos. Resultados encontrados no presente trabalho, sobre a biometria da cabeça e da cavidade craniana de ovinos deslanados, estão de acordo aos encontrados em caprinos, exceto no que se refere ao volume intracraniano dos ovinos, no qual foi encontrado diferença entre sexo masculino e feminino.

Foi possível notar, também, que os animais do sexo feminino possuem correlação entre o comprimento da cabeça e sua respectiva largura, bem como entre o comprimento da cabeça e o comprimento da cavidade craniana. Já nos animais do sexo masculino, não foram notadas as mesmas correlações. Todavia, Kalita et al. ${ }^{5}$, em seu estudo para determinar a dimensões da cabeça e da cavidade craniana em caprinos, encontraram os seguintes resultados: $24,74 \pm 0,21 \mathrm{~cm}$ de comprimento e 17,35 $\pm 0,24 \mathrm{~cm}$ de largura, sendo que os mesmo não apresentaram correlação com o comprimento da cavidade craniana nem com seu volume, que apresentaram, respectivamente, $11,71 \pm 0,08 \mathrm{~cm} \mathrm{e}$ $135,38 \pm 0,33 \mathrm{~cm}^{3}$. 


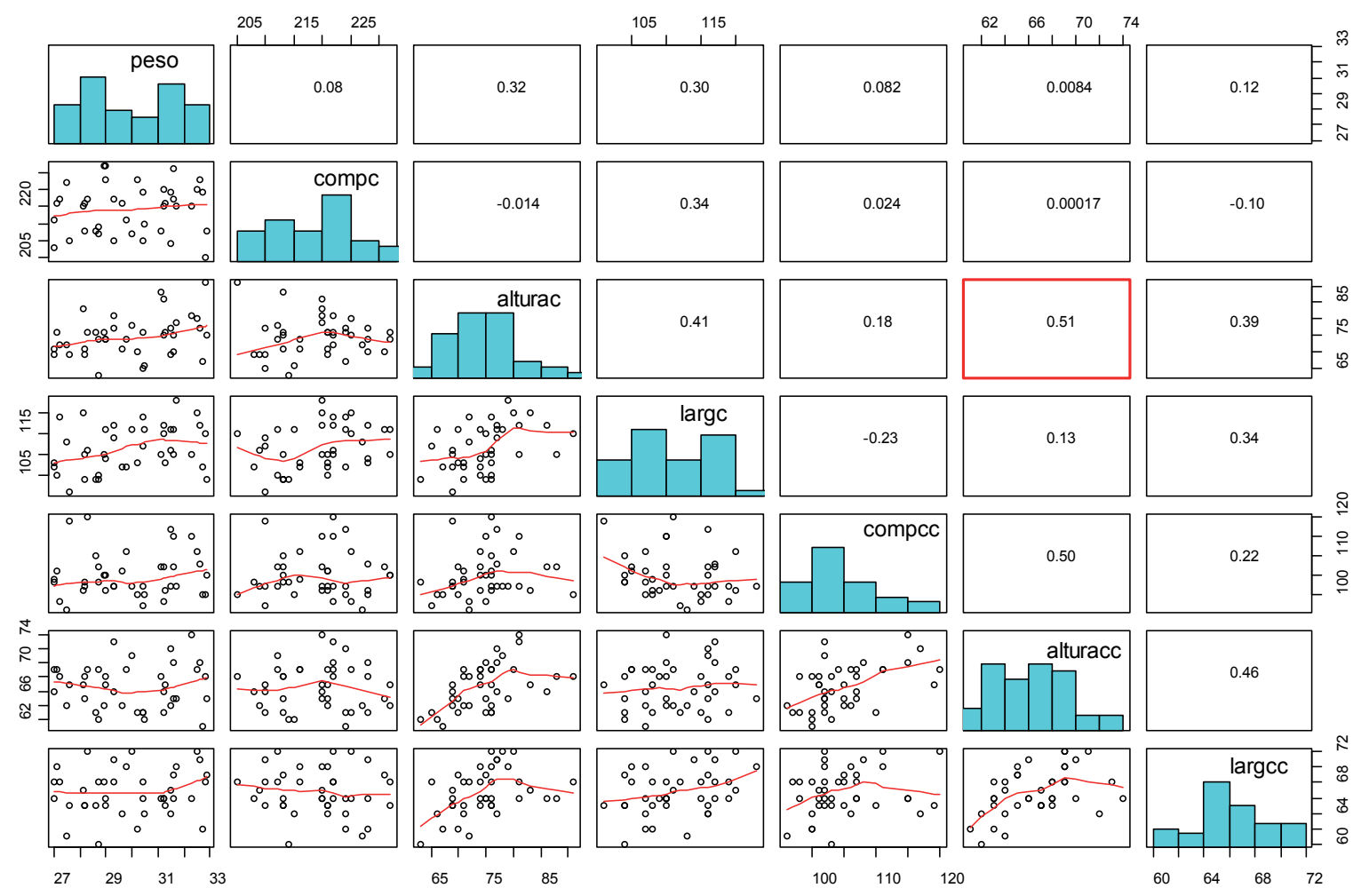

Legenda: peso - massa corporal / compc - comprimento da cabeça / alturac - altura da cabeça / largc - largura da cabeça / compcc comprimento da cavidade craniana / alturacc - altura da cavidade craniana / largcc - largura da cavidade craniana

Figura 2 - Gráfico evidenciando matriz de dispersão e coeficiente de correlação de Pearson entre massa corporal e dados da cabeça e cavidade craniana de ovinos deslanados sem raça definida do sexo masculino ( $\mathrm{r}$ $>0,5)$ - Petrolina - 2010

Estudando indivíduos do sexo masculino, foi possível constatar que possuem o volume da cavidade craniana maior que as fêmeas, sendo resultados semelhantes encontrados por Golalipour, Jahanshaei e Haidari, ${ }^{8}$ em estudo para definir a capacidade craniana em 808 pessoas normais, das quais 401 pertenciam ao grupo Turkman (198 homens e 203 mulheres) e 407 nativos Fars (200 homens e 207 mulheres), com idade entre 17-20 anos, em Gorgan Sudeste do Mar Cáspio fronteira com o Norte do Irã. Para tanto, foram obtidos dimensões da cabeça, como circunferência, comprimento e altura (com mensuração externa direta). A média e o desvio padrão da capacidade craniana dos Turkmans, para homens e mulheres, foram $1420,6 \pm 85 \mathrm{~mL}$ e $1227,2 \pm 120 \mathrm{~mL}$, respectivamente; e para os nativos do grupo Fars $1369 \pm 142 \mathrm{~mL}$ e $1215,8 \pm 125 \mathrm{~mL}$, para homens e mulheres, simultane- amente - mostrando diferença estatisticamente significativa $(\mathrm{P}<0,05)$, constatando que a capacidade craniana é mais elevada em homens do que em mulheres.

Com o presente trabalho evidenciou-se, ainda, que quanto maior a largura do crânio maior sua respectiva cavidade, - valores estes apresentados na tabela 1. Sarma ${ }^{6}$, estudando as características morfológicas da cabeça de 46 (quarenta e seis) caprinos da raça Kagani, obteve diferentes parâmetros cranianos, onde, para obtenção da biometria da cabeça foram utilizados escala e paquímetro, encontrando, para comprimento e largura da cabeça, 24,72 $\pm 0,93 \mathrm{~cm} \mathrm{e}$ $10.40 \pm 0,61 \mathrm{~cm}$, respectivamente, e para a realização da biometria da cavidade craniana, preencheu-se os forames da cavidade craniana que possuem conexão com a cabeça, sendo esta posteriormente preenchida com grãos de mostarda através do forame magno 
e, em seguida, colocados em proveta graduada para obtenção do volume da cavidade intracraniana, obtendo para esta, $113,0 \mathrm{~cm}^{3} \pm 0,84$, mostrando uma correlação linear da cavidade craniana com a largura da cabeça. No entanto, utilizando método semelhante ao descrito neste trabalho, para obtenção dos valores médios de volume da cavidade craniana Acer et al. ${ }^{9}$ avaliaram 28 (vinte e oito) crânios humanos, sendo no interior da cavidade craniana colocado um balão de borracha, o qual posteriormente era preenchido com água, sendo o líquido presente no interior do balão transferido para um recipiente de vidro graduado, obtendo média de $1311 \pm 133 \mathrm{~cm}^{3}$ para o volume da cavidade craniana.

Comparando os gêneros sexuais quanto aos valores médios para a cavidade craniana, reparou-se ser maior em machos que em fêmeas, sendo resultados semelhantes encontrados por Acer et al. ${ }^{13}$, em estudo para determinar a capacidade craniana, em 366 estudantes universitários saudáveis (226 homens e 140 mulheres), com idade entre 17 e 26 anos, utilizando as

\section{Referencias}

1. SALVIANO, L. M. C.; MASCIOLI, A. S.; ARAÚJO, M. M. Sistema atual e perspectivas da ovinocultura no Submédio São Francisco. In: SIMPÓSIO DE PRODUÇÃO ANIMAL DO VALE DO SÃO FRANCISCO, 1., 2006, Petrolina, PE. Anais... Petrolina, PE, 2006. p. 258-260.

2. DYCE, K. M.; SACK, W. O.; WENSING, C. J. G. Tratado de anatomia veterinária. Rio de Janeiro: Elsevier, 2004. 293 p.

3. EVANS, H. E.; DE LAHUNTA, A. Miller: guia para a dissecação do cão. 5. ed. Rio de Janeiro: Guanabara Koogan, 2001. p. 152-159.

4. GETTY, R. Sisson/Grossman: anatomia dos animais domésticos. 5. ed. Rio de Janeiro: Guanabara Koogan, 1986. v. 1, p. 29.

5. KALITA, A.; SARMA, K.; SHALINI, S.; ZAMA, M. M. S.; BILAL, A. Craniometrical study in bakarwali goats. Indian Journal of Animal Health, v. 43, n. 2, p. 180-184, 2004.

6. SARMA, K. Morphological and craniometrical studies on the skull of kagani goat (Capra hircus) of Jammu region. International Journal of Morphology, v. 24, n. 3 , p. $449-455,2006$

7. RODRIGUES, R. T. S.; MATOS, W. C. G.; WALKER, F. M.; COSTA, F. S.; WANDERLEY, C. W. S.; PEREIRA NETO, J.; FARIA, M. D. Dimensions of the cranium and of the cranial cavity and intracranial volume in goats (Capra hircus LINNAEUS, 1758). Journal Morphology Science, v. 27, n. 1, dimensões da cabeça (comprimento, largura e altura), as quais eram obtidas por craniometria, os resultados constataram uma média e desvio padrão para homens e mulheres de $1411,64 \mathrm{~cm}^{3} \pm 118,9$ e $1306,95 \mathrm{~cm}^{3} \pm$ 162,9 , respectivamente. Isso demonstra significativa diferença entre os sexos, o que permitiu aos pesquisadores constatar que a capacidade craniana é maior nos indivíduos do sexo masculino do que feminino.

\section{Conclusões}

Com o presente trabalho foi possível determinar que as fêmeas da espécie ovina apresentam cabeça com comprimento maior que os machos. Entretanto, os machos apresentaram altura e largura da cabeça com valores superiores aos encontrados nas fêmeas, bem como foi possível verificar que os machos tinham as dimensões da cavidade craniana superior às fêmeas (comprimento, altura, largura e volume da cavidade craniana). Desta forma, ficou evidente que quanto maiores forem as dimensões da cabeça maiores serão as do volume intracraniano.

p. 6-10, 2010.

8. GOLALIPOUR, M. J.; JAHANSHAEI, M.; HAIDARI, K. Estimation of cranial capacity in 17-20 years old in south east of caspian sea border (north of Iran). International Journal of Morphology, v. 23, n. 4, p. 301-304, 2005.

9. ACER, N.; SAHIN, B.; EKINCI, N.; ERGÜR, H.; BASALOGLU, $H$. Relation between intracranial volume and the surface area of the foramen magnum. Journal of Craniofacial Surgery, v. 17 , n. 2, p. 326-330, 2006.

10.SAHIN, B.; ACER, N.; SONMEZ, O. F.; EMIRZEOGLU, M.; BASALOGLU, H.; UZUN, A.; BILGIC, S. Comparison of four methods for the estimation of intracranial volume: a gold standard study. Clinical Anatomy, v. 20, n. 7, p. 766-773, 2007.

11.ROBINA, A.; REGODON, S.; GUILLEN, M. T.; LIGNEREUX, Y. Utilization of computerized tomography for the determination of the volume of the cranial cavity of the Galgo hound. Acta Anatomica, v. 140, n. 2, p. 108-111, 1991.

12.HWANG, Y. I.; LEE, K. H.; CHOI, B. Y.; LEE, K. S.; LEE, H. Y.; SIR, W. S.; KIM, H. J.; KOH, K. S.; HAN, S. H.; CHUNG, M. S.; KIM, H. Study on the korean adult cranial capacity. Journal of Korean Medical Science, v. 10, n. 4, p. 239-242, 1995.

13. ACER, N.; USANMAZ, M.; TUGAY, U.; ERTEKI'N, T. Estimation of cranial capacity in 17-26 years old university students. International Journal of Morphology, v. 25, n. 1, p. 65-70, 2007. 